\title{
Response to the letter to the editor "Nasal high-flow versus non-invasive ventilation in patients with chronic hypercapnic COPD” [Response to letter]
}

This article was published in the following Dove Press journal: International Journal of Chronic Obstructive Pulmonary Disease

\author{
Hubert Wirtz' \\ David Petroff ${ }^{2}{ }^{2}$ \\ Jens Bräunlich (1D) \\ 'Department of Respiratory Medicine, \\ University of Leipzig AöR, Leipzig, \\ Germany; ${ }^{2}$ Clinical Trial Centre, \\ University of Leipzig, Leipzig, Germany
}

\section{Dear editor}

We thank both authors for their thoughtful remarks to our study. We would like to point out that the trial was not formally designed as a non-inferiority study, but "to provide an estimate of the difference between the devices regarding $\mathrm{pCO}_{2}$ change". This choice followed lengthy discussions with the statistics experts of this institution acknowledging the arbitrary choice of a margin (for $\mathrm{pCO}_{2}$ reduction) of non-inferiority or equivalence. Defining these margins prior to the study would have had to be an estimate and we had aimed at a margin of $5 \mathrm{mmHg}$ for $\mathrm{pCO}_{2}$ derived from prior NIV studies. Instead of choosing arbitrary margins, we generated data to compare non-invasive ventilation (NIV) and nasal high flow (NHF) in stable hypercapnic COPD patients and concur with Elshof and Duiverman that this is an important topic due to lack of sufficient studies to date.

At the level of hospital or general policy, the authors are correct in their remark that non-inferiority in effectiveness does not suggest the need to make any changes unless other benefits are demonstrated. Our study suggests approximate equivalence of NIV and NHF in relevant outcomes, albeit not formally. Hence, at the level of choice for individual patients, such results are highly relevant since a larger variety of therapy options allows for better consideration of personal preferences. The observation that the proportion "of drop-outs is comparable between groups" merely indicates that there is no strong preference in the study population as a whole for a particular device, but does not preclude strong individual predilections.

In this study, an important feature was the fact, that blood gas measurements were taken hours after the termination of ventilation support treatment. Thus, the differences in $\mathrm{pCO}_{2}$ were somewhat smaller for both types of device compared to an in-hospital situation where blood gases are measured shortly after termination of ventilatory support. ${ }^{1}$ An additional graphical illustration of the $\mathrm{pCO}_{2}$ before and following each device arm is shown in Figure 1. However, the $\mathrm{pCO}_{2}$ decrease in our study was comparable to most cited studies by other authors despite slightly different pressure support values and reduced usage times.

Elshof and Duiverman are right to note that $201 / \mathrm{min}$ is not what would have been chosen if one were to start a study today. However, at the time the study was conceived, machines delivering more than 201/min were not available and thus we had to stick to the protocol and provide all patients with the same NHF device. The newer models of
Correspondence: Jens Bräunlich Department of Respiratory Medicine, University of Leipzig AöR, Liebigstrasse

20, Leipzig 04103, Germany

Tel +49492 198 I598

Email highflow@web.de 


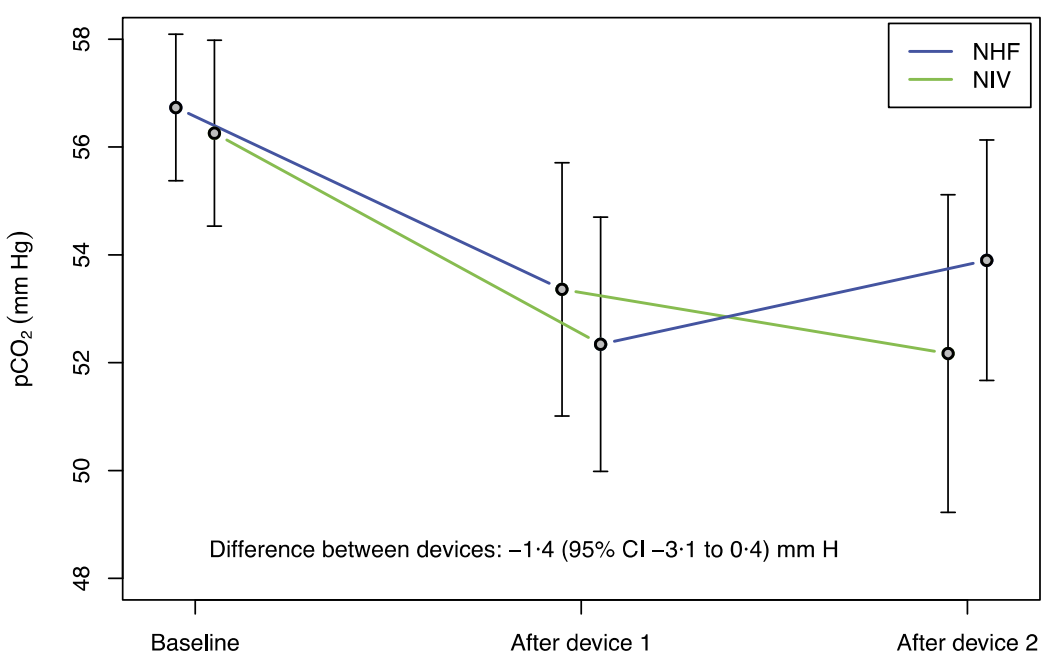

Figure I Partial pressure of carbon dioxide in capillary blood $\left(\mathrm{pCO}_{2}\right)$ is shown for each device and time point. Whiskers depict $95 \%$ confidence intervals.

NHF deliver higher flows and as cited by Elshof and Duiverman also have the potential to lower $\mathrm{pCO}_{2}$ more efficiently. This point indicates, as stated in our discussion, that the effect demonstrated here is most likely a conservative view comparing an early NHF device to standard NIV.

\section{Disclosure}

Dr. Bräunlich reports grants and non-financial support from TNI Medical AG during the conduct of the study; and grants, personal fees and non-financial support from TNI Medical AG and personal fees from Fisher \& Paykel, outside the submitted work. The authors report no other conflicts of interest in this communication.

\section{Reference}

1. Bräunlich J, Seyfarth H-J, Hubert W. Nasal high-flow versus noninvasive ventilation in stable hypercapnic COPD: a preliminary report. Multidiscip Respir Med. 2015;10:27. doi:10.1186/s40248015-0019-y

Dove Medical Press encourages responsible, free and frank academic debate. The content of the International Journal of Chronic Obstructive Pulmonary Disease 'letters to the editor' section does not necessarily represent the views of Dove Medical Press, its officers, agents, employees, related entities or the International Journal of Chronic Obstructive Pulmonary Disease editors. While all reasonable steps have been taken to confirm the content of each letter, Dove Medical Press accepts no liability in respect of the content of any letter, nor is it responsible for the content and accuracy of any letter to the editor.

\section{Publish your work in this journal}

The International Journal of COPD is an international, peer-reviewed journal of therapeutics and pharmacology focusing on concise rapid reporting of clinical studies and reviews in COPD. Special focus is given to the pathophysiological processes underlying the disease, intervention programs, patient focused education, and self management protocols. This journal is indexed on PubMed Central, MedLine and CAS. The manuscript management system is completely online and includes a very quick and fair peer-review system, which is all easy to use. Visit http://www.dovepress.com/testimonials.php to read real quotes from published authors. 